\title{
Paralelas e tangentes: A poética decadentista em Augusto dos Anjos e Antônio Nobre
}

\author{
Rogério Caetano de Almeida ${ }^{1}$
}

\begin{abstract}
RESUMO: Este texto desenvolve uma análise comparativa entre obras de Augusto dos Anjos e Antônio Nobre no que diz respeito aos elementos decadentistas presentes em textos selecionados previamente para a construção de poéticas com características da modernidade.

ABSTRACT: This text develops a comparative analysis between works by Augusto dos Anjos and Antonio Nobre in what it refers to the decadentist elements that are present in previously selected texts for the construction of poetical with characteristics of modernity.
\end{abstract}

PALAVRAS-CHAVE: Decadentismo; Augusto dos Anjos; Antônio Nobre.

KEYWORDS: Decadentism; Augusto dos Anjos; Antônio Nobre.

Tentaremos, através de análises comparativas de poemas escolhidos do "Só", de Antônio Nobre, e do "Eu", de Augusto dos Anjos, uma pequena contribuição para o entendimento da obra dos dois autores e para uma melhor compreensão do Decadentismo enquanto expressão literária que inquieta o pesquisador, por meio de sua fundamental importância ao que se convencionalizou chamar de "tradição de ruptura" na cultura ocidental.

Assim, levantamos a questão: Antônio Nobre e Augusto dos Anjos são poetas que rompem com o cânone literário do início do século XX no que diz respeito às literaturas em língua portuguesa? A pergunta suscita outras: São eles poetas decadentistas? Quais aspectos do decadentismo estão presentes em seus textos? A arte decadentista é que finalmente rompe com a tradição clássica?

Com o levantamento de tais questões, ressaltamos, ainda, a necessidade de repetir alguns temas históricos, sociais, biográficos, filosóficos e estéticos já conhecidos, porém necessários para responder às questões. Iniciemos pelo contexto histórico português.

Os lusitanos são advertidos pela Inglaterra com o Ultimatum no que diz respeito às colônias africanas que se interpunham ao intento bretão de fazer um caminho "do Cabo até o Cairo". Com isto, os portugueses perderam parte de suas terras para exploração em

\footnotetext{
${ }^{1}$ Mestrando em Estudos Comparados em Literaturas de Língua Portuguesa, FFLCH-USP. Pesquisa: O corpo grotesco como elemento de construção poética nas obras de Augusto dos Anjos, Mário de Sá-Carneiro e Ramón López Velarde. E-mail: rogalmeida01@hotmail.com
} 
África, além de admitirem intervenção inglesa em questões nacionais. Um pouco antes (1808), a pátria fora invadida pelo exército de Napoleão e, em 1822, o Brasil se tornara independente, o que, para Portugal, significou uma amputação de boa parte do seu território e representou um enorme prejuízo, pois, com o Pacto Colonial, o país comercializava $92 \%$ de sua economia com o Brasil.

Antônio Nobre, um "sebastianista", representa em seus trabalhos parte dos anseios populares portugueses. Há em Portugal um certo ar de desconfiança e desânimo a ponto de D. Sebastião ser considerado "O Desejado" para o poeta e outros artistas da época. Fernando Pessoa, quando analisando o grupo do qual Antônio Nobre fazia parte, mencionao dizendo ser uma das maiores inspirações portuguesas:

"De Antônio Nobre partem todas as palavras com sentido lusitano que de então para cá têm sido pronunciadas [...]. Ele foi o primeiro a pôr em europeu este sentimento português das almas e das coisas [...]. Ele vem no Outono e pelo crepúsculo. Pobre de quem o compreende e ama! [...] Quando ele nasceu, nascemos todos nós.”(In: FERREIRA, 1989, p. 48.)

Pessoa, em suas palavras finais do referido texto, identifica algo nascente na obra do poeta. Talvez seja o que chamamos aqui de modernidade. Segundo os estudos de Mário Praz, a modernidade se desenvolve no final do século XIX com os decadentistas, e os aspectos analisados posteriormente na obra de Antônio Nobre confirmam estes traços.

Em Augusto dos Anjos temos outras especificidades. O poeta nasce na Paraíba em 1884. A família de sua mãe pertence aos donos de engenho falidos do início do século. O problema financeiro acompanhará o poeta até o fim de sua vida. Em 1912, publica "Eu". O livro é bem recebido por alguns críticos, mas a maioria não o compreende e estranha a obra. Em 1914, vai para o interior do Estado de Minas Gerais para assumir o cargo de diretor em uma escola, contudo morre três meses depois. A partir de 1920, seu livro começa a ser reeditado com versos inéditos e tem um extraordinário sucesso de crítica e público.

No estudo de Eudes de Barros, identificam-se algumas semelhanças entre C. Baudelaire e A. dos Anjos, que o autor chama de patologia estética: autofobia (medo de si mesmo e de sua condição artística); ambivalência; materialismo supersticioso; gosto pelo repugnante; trazem o monstruoso, o macabro, o repulsivo como elementos fascinantes em um sentido estético e sensual; adaptações de circunstâncias líricas e sacras às suas abominações favoritas - verme, fedor, podridão. Algumas das características citadas no estudo são decadentistas por excelência e serão utilizadas na análise posterior. 
Não podemos deixar de esclarecer que, no Brasil, também há uma certa euforia. Se no contexto europeu, como dito aqui, há a Belle Epoque, no contexto brasileiro há uma crença de que o país se elevará de sua pobreza através do advento da República. Porém, Augusto dos Anjos é descendente das oligarquias decadentes, além de, como intelectual, discordar do pensamento positivista tão em voga também no Brasil da época.

\section{Decadentismo}

O Decadentismo surge na França do final do século XIX enquanto reação ao pensamento positivista, evolucionista e naturalista. O início do pensamento decadente se desenvolve com Schopenhauer, depois com Baudelaire, R. Wagner, Nietzsche e Bergson. Porém, é em Mallarmé que temos um Decadentismo definitivo.

O movimento decadente é formado pela elite intelectual do final do século XIX e se contrapõe à Belle Epoque, vivida pelas classes baixas e aos mais abastados. O sentimento de que o mundo vive uma época de paz e tranqüilidade se esfacelará em 1914. Pelo contrário, os intelectuais "percebem um certo ar de cansaço, uma vaga idéia de algo que morre, um mundo em decomposição", como dirá Fúlvia Moretto. Algo muito similar ao sentimento que acompanha des Esseintes, o personagem de A Rebours, de J.-K. Huysmans.

Em contrapartida, há uma vontade de lutar por parte da intelectualidade. Essa luta contra o fastio se dará no campo das artes. A luta é estética e retoma a grande transformação que o Romantismo trouxe ao campo das artes anos antes. O Decadentismo e o Simbolismo eram, na verdade, conclusões dos ideais românticos, todavia já travestidos de traços não pertencentes a estes. A vontade do indivíduo de se libertar se potencializa no "eu"; porém, mais adiante, no decadentismo, essa vontade não sacia, e sim traz um vazio psicológico profundo. Além disso, temos a ruptura do homem com o pensamento teológico e platônico e, assim, chegamos aos estudos de F. Nietzsche - o mundo sensível, do corpo sensual, é o seu objeto.

O inconsciente controla as vontades desse corpo. Assim, por parte dos Simbolistas, há uma tentativa de busca das vontades inatingíveis. No decadentismo, ao contrário, paira um certo ar de imutabilidade. Enquanto os simbolistas buscam as vontades, os decadentes fazem o contrário: demonstram um certo desprezo pela Vontade e contrapõem-na à Inteligência. A Inteligência (mundo sensível) trará uma solução: o não-desejo. Portanto, a 
libertação do artista se realizará através da arte e esta será contemplada com um certo tédio, que será evitado pela procura de sensações refinadas.

A inquietação metafísica para o decadentista é muito cara. Ela vem através do signo (corpo sensível), que, no todo do poema, será transmitida, como a música, de forma múltipla. O artista, a partir de então, completamente cônscio de seu fazer, reflete, mesmo que de forma indireta, sobre o seu labor, o seu fazer poético. O problema da significação das palavras se torna o fulcro da poética dentro do decadentismo, e esse ideal estético de perfeição, muito trabalhado por Mallarmé e pelos poetas posteriores, é o grande objetivo do fazer poético.

A transgressão através de um ato estético é diferente da transgressão romântica no sentido de fugir da realidade para descobrir novas realidades. Destarte, a arte decadentista é tão somente um ato estético que se preocupa com seu próprio fazer. Com base no trabalho de Fúlvia Moreto, temos outras características do decadentismo que são decorrências da reflexão sobre o fazer poético: concepção pessimista da vida (apesar de Anatole Baju negar esta em um texto presente no próprio livro); interesse pelo universo interior e secreto onde, antes de Freud, serão descobertas as realidades do inconsciente; fantástico não-demoníaco que procura uma profunda análise psicológica; fascínio pelas arquetípicas lendas antigas e medievais, além da bíblicas Salomé, que foi chamada de "deusa da decadência"; gosto pela natureza petrificada; tema do reflexo na água, transparente ou espelhada (complexo de Édipo extremado, auto-contemplação); utilização da morte como tema constante.

\section{Aspectos decadentistas em "Balada do caixão"}

O meu vizinho é carpinteiro, Algibebe de Dona Morte, Ponteia e cose, o dia inteiro, Fatos de pau de toda a sorte: Mogno, debruados de veludo, Flandres gentil, pinho do Norte... Ora eu que trago um sobretudo Que já me vai a aborrecer, Fui-me lá, ontem: (era Entrudo, Havia imenso que fazer...) - Olá, bom homem! Quero um fato, Tem que me sirva? - Vamos ver... Olhou, mexeu na casa toda.

- Eis aqui um e bem barato.

- Está na moda? - Está na moda. (Gostei e nem quis apreçá-lo: 
Muito justinho, pouca roda...)

- Quando posso mandar buscá-lo?

- Ao pôr-do-Sol. Vou dá-lo a ferro;

(Pôs-se o bom homem a aplainá-lo...)

Ó meus Amigos! Salvo erro,

Juro-o pela alma, pelo Céu;

Nenhum de vós, ao meu enterro,

Irá mais dândi, olhai! do que eu!

(A. Nobre, 1891)

Em um tom de irreverência, o poema se inicia com um diálogo entre o eu-lírico e seu vizinho, um homem que constrói as roupas para 'Dona Morte'. A 'personagem' do poema carrega um sobretudo (metáfora de sua própria vida) que o incomoda, por isso vai pedir uma outra vestimenta. Em um diálogo, interpela seu vizinho em busca de um traje para si mesmo. O homem encontra um que é bonito, barato e está na moda. Então, o eulírico pergunta quando pode mandar buscar sua vestimenta fúnebre e o outro responde que ao entardecer estará pronto e começa a aplainar a madeira para fazê-lo dentro do prazo. $\mathrm{O}$ tom de desprezo da voz poemática em relação à sua vida é uma marca do tédio desenvolvido pelos decadentistas. Na quadra final, a conversa não é mais com o vizinho. $\mathrm{O}$ poeta utiliza a generalização (“Ó meus Amigos”) para comunicar sua morte a todos. Esta ocorrerá no final da tarde e, de forma jocosa, diz ser o mais dândi em seu enterro.

A principal característica que se identifica em uma primeira leitura do texto é a versatilidade do poeta no que diz respeito à linguagem, que é coloquial. Ao analisarmos as palavras escolhidas pelo autor, percebemos, porém, uma musicalidade muito apurada e sensível. Seguindo os decadentistas franceses, a rima do texto possui um paralelismo musical de nível tão elevado que lembra um jogral medieval, fazendo com que o leitor fique inebriado com o efeito construído na sonoridade das palavras. Destarte, o tom coloquial e a melodização sugerem uma morte tranqüila. Esta aparece tão leve que o corpo da voz-poema plastifica-se ironicamente em uma beleza refinada e excêntrica - o dandismo.

Como foi dito acima, o estudo de um poeta decadente é o do som e o próprio objetopalavra. Ressaltamos que o substantivo, enquanto objeto-palavra, vivifica o ser no qual se refere escrito preferencialmente com letra maiúscula. Os substantivos que aparecem no poema nunca se referem ao eu-lírico: dizem respeito a seu vizinho, ou ao tempo, ao material do caixão, etc. Quanto ao verbo, quando se refere ao poeta, mesmo sendo de ação, 
traz uma paralisia da personagem principal: parece-nos que a única ação efetiva é carregar sua vida como um fardo pesado e, no final, a ação é oratória: ("Quando posso mandar buscá-lo?"; “Ora eu que trago um sobretudo/ Que já me vai a aborrecer"; "Salvo erro,/ Juro-o pela alma, pelo Céu”; “- Olá, bom, homem! Quero um fato”.)

A ironia do autor é muito sutil e ácida. O tema mais recorrente na poética decadente é o da morte, mas esta aparece no poema de um jeito diferente: ela representa uma beleza refinada, rara, estética e estática. A morte carnavalizada virá logo depois do Entrudo ${ }^{2}$, ou seja, após uma festa. A figura da morte no poema não aparece de forma direta, mas toda a atmosfera do texto se refere à morte como uma busca pelo inatingível. A Morte, personificada, traz a lembrança daquelas musas decadentistas que fazem os homens buscálas incondicionalmente (como Salomé, que pede a cabeça de João Batista).

Porém, não podemos deixar de pensar que em toda a "trama" do poema há um certo ar fantástico (destacando a previsibilidade da morte) e, por isso, de outra forma, todo o fato ocorrido pode se realizar, também, na esfera do inconsciente, do sonho incontrolável, do universo da vontade estética de morrer apenas no texto, atingindo o prazer estético através da matéria como algo místico e paradoxal (madeira e vizinho, por exemplo, que são substantiváveis - ou mesmo o próprio título do poema e a realização do enterro em si).

No entanto, o autor conclui o poema convocando seus amigos para seu enterro. Neste momento, temos a contemplação narcísica, comum aos decadentistas. Além de causar estranhamento ao leitor, esta mórbida autocontemplação pode ser uma estratégia do autor para fugir do tédio através de uma ironia que se aproxima do grotesco e, quando pensamos no eu-lírico morto, em um sentido real, todo o universo do texto se desfaz também.

\footnotetext{
${ }^{2}$ Entrudo é uma festa regional de Trás-Os-Montes que ocorre no período do Carnaval e se realiza com a disputa entre homens e mulheres pela divisão de um burro. Para isso, os jovens discursarão sobre quem merece a herança utilizando textos paródicos e se baseiam na experiência dos mais velhos para realizá-los. Há um grupo de mascarados que escuta silenciosamente os realizadores das diabruras escritas, depois serão perseguidos por aqueles - a perseguição ocorre até a terça-feira, quando se realiza um grande banquete de carne de porco, marcando o início de um jejum de carne até o final da Quaresma. Na festa ainda temos o desfile dos Caretos (diabos que perseguem as moças, mesmo invadindo suas casas para a realização de uma dança um tanto erótica com chocalhos que fazem muito barulho - tudo vale a pena para chocalhar com as moças e confundir o barulho destes com os risos das moças) e o duelo destes com as Matrafonas (mulheres vestidas de homens e vice-versa).
} 


\title{
Aspectos decadentistas em "Vozes de um túmulo"
}

\author{
Morri! E a Terra - a mãe comum - o brilho \\ Destes meus olhos apagou!...Assim \\ Tântalo, aos reais convivas, num festim, \\ Serviu as carnes do seu próprio filho! \\ Por que para este cemitério vim?! \\ Por quê? Antes da vida o angusto trilho \\ Palmilhasse, do que este que palmilho \\ E que me assombra, porque não tem fim! \\ No ardor do sonho que o fronema exalta \\ Construí de orgulho ênea pirâmide alta... \\ Hoje, porém, que se desmoronou \\ A pirâmide real do meu orgulho, \\ Hoje que apenas sou matéria e entulho, \\ Tenho consciência de que nada sou!
}

(A. dos Anjos, 1905)

A única conclusão que se tem sobre a obra de Augusto dos Anjos é a completa singularidade estética que possui. Estruturalmente, o poema de Augusto dos Anjos é um soneto que possui versos decassílabos alexandrinos e sáficos com rimas opostas e paralelas nas quadras (abba). Sonoramente, identificamos a anáfora dos termos "hoje" e "por que". Temos, ainda, a aliteração do som nasalizado "m" no início do poema; a partir da segunda estrofe, identificamos uma troca da preponderância do som "m" pelo "p" e pelo "q" oclusivos. Nos dois tercetos, temos sons diversos: as nasais e as oclusivas dividem espaço com as constritivas fricativas.

Quanto à análise de conteúdo do poema, percebemos que o texto de Augusto dos Anjos possui um eu-lírico que, em forma de monólogo, descreve os pensamentos de sua “alma" após ser enterrado. O autor nos envolve com seu procedimento, pois, à primeira vista, é uma única voz a se manifestar, e o título do poema, de forma contraditória, coloca essa voz no plural. Com todas as vozes que o informam sobre seu estado de decomposição corporal, o eu-lírico do poema adquire a consciência de nada ser perante a natureza, o universo, a mãe Terra, o próprio sonho e, por fim, a sua própria condição humana. O NadaSer presente no texto remete-nos à aniquilação do Mundo das Representações de Schopenhauer. 
O problema das vozes vai nos encaminhar na análise de um poema que podemos chamar momentaneamente de fragmentário. No primeiro quarteto, o eu-lírico identifica-se morto e, logo depois, descreve um banquete grotesco em que se serve carne humana. Tântalo, talvez uma ave ciconiforme (garça, cegonha, flamingo, por exemplo), talvez um ser mitológico, serve (e come) as carnes de seu próprio filho aos convivas de seu banquete de forma inocente. No segundo quarteto, o eu-lírico nos indaga sobre o motivo pelo qual vai para aquele cemitério que parece desagradá-lo. No primeiro terceto, temos uma atmosfera de sonho sendo construída e esta se torna derradeira no segundo terceto, onde a "pirâmide alta que se desmoronou" vai tomar consciência de nada ser.

$\mathrm{Na}$ realização do banquete de decomposição, adotaremos uma leitura em que todas as vozes pertencem ao conjunto da festa, formando uma única voz possível - a polifônica. A desordem em que os fatos do poema são descritos nos levam a pensar em um extremado ato da inconsciência: possuir uma organização própria, não-linear, antagônica ao esteticismo tradicional. No momento em que o eu-lírico questiona sua existência quando presente em um banquete antropofágico e bestial, há uma espécie de autodeglutição corporal e grupal, porém petrificada e congelada. Podemos, também, pensar a imagem enquanto destruição da Vontade de Schopenhauer; portanto, o refinamento estético decadentista é atingido com a criação de um ambiente raro, estranho à realidade comum. Em um passeio pelo seu inconsciente, o eu-lírico contempla (e participa) esteticamente da autodeglutição. Isto faz com que o poema transite, com a figura do Tântalo, por exemplo, pelo limite do fantástico não-demoníaco característico na arte decadentista, pois o banquete é realizado em uma atmosfera real, mas o eu-lírico é um morto-vivo que participa e contempla tudo de uma forma que o faz concluir com um certo pessimismo: "nada sou."

A contemplação do escatológico e pútrido ocorre de forma estética, como diz Eudes de Barros, ou seja, imaginamos uma beleza implícita ao banquete. O campo de ação do eulírico do poema se resume à participação no banquete antropofágico e a uma certa observação de que esse ato não influencia na evolução de seu ser, na metafísica de seu corpo e sua alma pós-morte. Assim, a autocontemplação acaba se transformando em uma análise desanimada de seu ser, ou seja, o "viver é sofrer" schopenhauriano se estende ao pós-vida, pois nada acontece a não ser um angusto, um bloqueio. Portanto, temos pressupostos decadentes - a natureza petrificada e a temática da morte.

Averiguando a imagem utilizada pelo poeta da pirâmide, percebemos que, na simbologia, ela representa um estado ambivalente de morte terrena e ascensão e 
identificação com o rei-sol egípcio. No poema, temos a ambivalência de morrer de forma física (a consciência abandonando o corpo) e metafísica, que é quando a consciência deixa de existir e se transforma em um nada-ser, ou seja, o que resta é apenas um sujeito-objeto em decomposição, finito, que perece justamente nessa limitação.

Em seu conjunto, o poema apresenta aspectos da teoria decadentista - que podem ser observados quando o analisamos em partes -, tais como os que já foram apontados aqui. Porém, quando analisamos o todo da obra, parece-nos que seu conjunto decadente seria algo similar a uma tela com corpos em decomposição, deglutidos, que trazem a idéia de um nada após todo o escrutínio das vísceras e do irrealizável dessa cena (que acontece nas esferas da inconsciência). Esse nada vem logo após um prazer estético paradoxal que é simplesmente a observação da obra enquanto realidade passível apenas dentro da própria obra de arte.

\section{Considerações finais}

Os dois poetas são precursores da tradição de ruptura do cânone literário? Primeiramente, devemos dizer que toda escola literária que surge rompe com modelo(s) anterior(es). Igualmente, Antônio Nobre e Augusto dos Anjos não podem ser analisados apenas como poetas decadentistas. Inseridos em uma época em que a modernidade surge na poesia, os dois autores inovam em alguns aspectos.

Em Augusto dos Anjos, identificamos o estranhamento através das temáticas e do vocabulário científico de que se utiliza o artista, além de suas rimas extravagantes, apesar de um certo conservadorismo formal. Ou seja, o autor sabia ser um inventor de poesia e linguagem, não simplesmente um poeta.

Antônio Nobre foi acolhido de forma receptiva por parte da crítica portuguesa, mas logo depois há um certo desprezo. Fernando Pessoa o invoca como o pai da modernidade da poesia portuguesa. Ele consegue misturar as falas do populacho da região de Trás-OsMontes com uma temática extremamente profunda e complexa, ou seja, temos uma marca de ruptura com a poesia anterior. Assim sendo, os dois são poetas da modernidade. 


\section{Referências bibliográficas}

ANJOS, Augusto dos. Eu e outras poesias. 43ª edição. Rio de Janeiro, Bertrand Brasil, 2001.

BALAKIAN, Anna. O Simbolismo. Trad. José Bonifácio A. Caldas. 1ªed. $2^{\mathrm{a}}$ tiragem. São Paulo, Perspectiva: 2000.

MORETTO, Fúlvia L. M. (organizadora). Caminhos do Decadentismo Francês. São Paulo, Perspectiva/ Edusp, 1989.

NIETZSCHE. Friedrich. O Nascimento da Tragédia ou Helenismo e Pessimismo. Trad. de J. Guinsburg. $2^{\mathrm{a}}$ ed. $7^{\mathrm{a}}$ reimpressão. São Paulo, Cia. Das Letras, 2003.

NOBRE, Antônio. Só. $5^{\text {a }}$ edição. Porto, Araújo e Sobrinho, 1931.

Só. Introd. de M. Ema T. Ferreira. Editora Ulisseia, 1989.

SCHOPENHAUER, Arthur. O Mundo Como Vontade e Representação - III Parte. Trad. de W. Leo Maar e Maria Lúcia Mello e Oliveira Cacciola. Assessoria de Rubens R. T. Filho. São Paulo, Editora Nova Cultural, 1999. 